\title{
An Assessment of Constraints and Cultural Constructs That Influence the Perception and Utilizing Indigenous Environmental Protection Ethics: The Case of Madda Walabu, Delomana and Ginner
}

\author{
Ketema Tafa Biratu \\ Department of Civics and Ethical Studies, Madda Walabu University, Bale Robe, Ethiopia \\ Email: ketematafa2014@gmail.com
}

How to cite this paper: Biratu, K.T. (2020) An Assessment of Constraints and Cultural Constructs That Influence the Perception and Utilizing Indigenous Environmental Protection Ethics: The Case of Madda Walabu, Delomana and Ginner. Open Journal of Social Sciences, 8, 51-59.

https://doi.org/10.4236/jss.2020.81004

Received: December 17, 2019

Accepted: January 5, 2020

Published: January 8, 2020

Copyright $\odot 2020$ by author(s) and Scientific Research Publishing Inc. This work is licensed under the Creative Commons Attribution International License (CC BY 4.0).

http://creativecommons.org/licenses/by/4.0/

\begin{abstract}
The central purpose of this study was to assess constraints and cultural constructs that influence the perception and utilizing indigenous environmental protection Ethics. Previously, much emphasis has not been given to it. Quantitative method was used to achieve the objectives of the study. Relevant information for this research has been gathered from both primary and secondary sources. The data obtained from both primary and secondary sources were organized and analyzed through content analysis. The findings of this study reveal the constraints and cultural constructs that influence the perception and utilizing indigenous environmental protection Ethics with particular emphasis Madda Walabu, Delomana and Ginner. Indigenous environmental protection Ethics had been practiced by the Oromo society for a long time. It had been guiding and regulating the life of the Oromo in relation to other peoples and their environment. The findings further showed the constraints and cultural constructs of perception and utilizing indigenous environmental protection Ethics.
\end{abstract}

\section{Keywords}

Indigenous, Indigenous Environmental Ethics, Constraints, Cultural Constructs, Bale Oromo

\section{Introduction}

Human behavior towards environment in a particular society is guided by the 
prevailing culture and perceptions of the entire environment. It is obvious that indigenous environmental protection Ethics plays an important role for future progress and development of the community. Different environmental ethicists provide different meanings of environmental ethics. But the working thoughts are the moral relationships between human beings with the rest of nature (Andrew Light et al., 2003) [1].

Indigenous environmental protection Ethics of the Oromo society through which the society administered, defended their territory, maintained and developed their economy and it is the self sufficient system that influenced every aspect of Oromo society, from politics to religion until recently. Indigenous environmental Ethics have been governing the direction and day-to-day lives of the people of Oromo society particularly protecting natural resources [2].

According to Hayden (1994), there are numerous and different indigenous environmental ethics all over the world which are not yet explored. Accordingly, different people in the world have their own unique environmental ethics since it is related with the values of society [3].

Indigenous environmental protection Ethics is based on local resources and time-tested environmental management practices, which are embedded in community practices, culturally based value systems, systems of production and consumption (Sabine Hausler, 1995: 184) [4].

Many of today's environmental problems are increasingly the outcomes of individual actions, personal consumer decisions, and the activities of small and large businesses. Nevertheless, the fact remains that the healthiness of the world's economy and people is inextricably bound to the wellbeing of the environment. This implies that now, much more than previously, there is a greater need to understand patterns, connections, systems and root causes of the degrading environment [5]. One veritable tool for achieving this feat is a proper understanding and the application of indigenous environmental ethics. Most people believe that the present environmental problems need a complex scientific device and knowledge. Another underlying reason might be that since science provides objective answers which are based on fact in a field where otherwise emotions and conflicts of interest abound, it is only natural that we should make use of science to guide us in this matter.

However, in recent years, environmental philosophers and other thinkers challenged the supposition that only science and technology would bring a solution for environmental problems. For instance, Stenmark (2002) argues, "it has often been observed that environmental problems have an ethical dimension." These philosophers, however, don't deny the relevance of science and technology in our understanding about environmental problems. Rather they want to incorporate the ethical dimension of environmental problems to science and technology [6].

Indigenous environmental Ethics is holistic system that occupies the environmental, social and economic aspects of the Oromo people's lives. Their indigenous environmental ethics is found in their cultural practices, institutions, 
histories and practices. If this indigenous ethics can be joined, then it is believed that it can be a means through which sustainable development, equitable use of natural resources can be achieved [3].

Environmental ethics nearly always stress the need for increased or improved caring in the form of moral regard for nonhuman others and ecological systems, and the lack of such regard is commonly cited as a fundamental cause of environmental damage and destruction [5]. When we look at environmental change, there is a need to clearly assess and understand the consequences of natural changes, human activities indigenous environmental protection Ethics. Despite the fact that the role of indigenous environmental protection Ethics in the overall livelihood improvement and efforts is not well-considered in most of our societies, it is becoming obvious that almost no effort excluding the genuine involvement of indigenous can be achieved as required [2]. As per the researcher observation and familiarity about the area, it is known that the majority of the environmental protection systems among Bale Oromo are settled through indigenous procedures. Moreover, different authors have studied but they did not discuss the constraints and cultural constructs of indigenous environmental protection Ethics in the selected area.

Africans, as any other people elsewhere, have their own philosophy of life. They have a different indigenous ethics by which they see and interact themselves [6]. The study would be significant from the following perspectives. First, it would provide valuable information and understanding about constraints and cultural constructs that influence the perception of indigenous environmental protection Ethics. Second, it would reveal the preference of people related to utilizing indigenous environmental protection Ethics and the rationale behind it. Third, the finding of the study believed to be used by the concerned bodies to consider and preserve indigenous ethics and values. Further, the result of the study had contributed to the limited literature on indigenous environmental protection Ethics.

The research is designed and employed a qualitative approach with the objective to study the issue in depth and to get adequate data, to collect the necessary and relevant data; the instruments employed for this study were key informant interviews, focus group discussion, and observation. Data sources included both primary and secondary data. The primary sources of data were community elders, Abbaa Gadaas, both male and female youth, women and culture and tourism staff members of the selected woreda whereas the secondary sources included the relevant and related literatures, books and journals to enrich the primary data. Data that was collected through the above-motioned tools were organized and analyzed through ethnographic content analysis.

\section{Research Approach}

The approach followed in this research is mainly qualitative in nature since the main objective of this research is assessing constraints and cultural constructs that influence the perception and utilizing indigenous environmental protection 
Ethics of the Bale Oromo people. Therefore, to conduct an in-depth study in this area qualitative approach is more pertinent for this study since qualitative methodology enables in-depth investigation of a specific phenomenon in particular environment such as groups of people, institutions, cases, and geographical areas. As the researcher affirms that the central area of the research is the Bale zone purposively Madda Walabu, Delomana and Ginner woreda.

To make this research credible both primary and secondary data sources were used. Both primary and secondary data sources were enriched through primary and secondary data collection methods. The primary data were collected through an interview, observation and focus group discussions. While, the secondary data were collected through document analysis from different sources like books, journal articles, and documents which have a direct relevance with the research.

The researcher analyzed, evaluate and synthesize those different views of the respondent through relating within the secondary sources. Thematic categorizations were drawn from the major points raised in the research questions. The data gained from differing sources were finally compared, analyzed, and synthesize with the purpose of critical examination of their various claims about the indigenous environmental protection ethics of the Bale Oromo people.

\section{Results and Discussion}

Analysis of the documents obtained from related researches shows that, as Oromo society has gone through dramatic social changes, many of its indigenous ethics have been affected negatively. There were no well documented records of indigenous resources. The main constraints faced Oromo community while they attempt to utilize indigenous environmental protection ethics is, the privatization sense and immigration of vast people who do not share the same norms, principles, cultures and values. This means, the indigenous people prefer to deal with their cases (environmental protection) with their own indigenous ethics whereas the strangers follow the statutory alternative legal system.

The other constraints of utilizing indigenous environmental protection, knowledge and Ethics are that indigenous technology and practice are not universally applicable, but are locally grounded. Because of the localization of indigenous knowledge systems, the local people do not have the intellectual resources to engage with global issues created by capitalism [7]. Their attempt to deal with new problems can only depend on the local pool of techniques, materials and genetic resources and other borrowed knowledge.

Modern education, market forces, foreign religions, poverty and government policies have eroded the indigenous environmental protection ethics in Oromia and in other parts of the world. Furthermore, the indigenous Oromo environmental protection ethics is being destroyed owing to the fact that many knowledgeable elders have passed away without heirs, who can transfer their knowledge to the young people (Workeneh, 2011) [8]. 
Gadaa as Oromo political culture provides many constructive features which are conducive for perception and utilizing indigenous environmental protection in turn for economic growth and development. Baxter (1993) argues that the Oromos do not classify particularly land and water, and hence territory as material resources which people can control or use because the utilization of all natural resources has a religious dimension across all Oromos since waaqa is involved in them. He further asserts that the proper allocation and use of natural resources in bound by ritual activities rather than by political territorial boundary [9].

\subsection{Constraints of Utilizing Indigenous Environmental Protection Ethics}

Even though the utilization of indigenous protection ethics has declining, the practice is not totally lost [7]. The outcome from the focus group discussions with most of elders of the study area indicates that, this interesting system of indigenous environmental protection ethics has been facing a serious threat from many sides. From time to time the smooth functioning of indigenous environmental protection ethics has been weakening. On the views of discussions with the elders and experts, constrains to utilization of indigenous environmental protection ethics was from external interventions like intervention of state, privatization sense and immigration.

Absence of a comprehensive land use plan for the country as a whole is considered to be one of the serious constrains to utilization of indigenous environmental protection ethics in this country to deal with environmental issues as decisions may be arbitrarily made, even against the interests of local communities [10]. This indicates severe constraints, particularly in the implementation of policies and strategies. Efforts so far have focused on developing to utilization of indigenous environmental protection ethics, while much has not been done at the field level. It is not enough to have good policies and strategies if they are not supported by capacity in the form of adequate numbers of qualified personnel, sufficient economic resources, institutions and organizations equipped to effectively implement the policies and strategies [11].

Another major constraint for the utilization of indigenous environmental protection ethics is the inadequate budget and lack of logistic support government has on the issues. In other terms the State has failed to put in place organizations that give strong support to the utilization of indigenous environmental protection ethics. The absence of effective institutions plus the weak law enforcement undermines the role of local communities, their traditional institutions and knowledge [12].

In Ethiopia also there is no institute who fund and study Indigenous sources which are the cornerstone for the development of the country in different angels. Misunderstanding these roles create confusion to the utilization of indigenous environmental protection ethics [8]. 


\subsection{Cultural Constructs That Influence the Perception and Utilizing of Indigenous Environmental Protection Ethics}

A consideration of Cultural Constructs that Influence the Perception and Utilizing of Indigenous Environmental Protection Ethics, the total of all human beings, is vital in any discussion on environmental change [13]. There is no doubt that population changes and environmental factors influence each other. There are now glimpses of hope in some regional laws as they expressly provide for the issuance of land use plans, at least at regional level [14].

Improving comprehensive participation in the Perception and Utilizing of Indigenous Environmental Protection Ethics should be promoted more widely to make the local communities the immediate custodians of the Indigenous Environmental Protection Ethics [15]. They are the stakeholders most concerned about the state of the Indigenous Environmental Protection Ethics as they are sources and owner on them for a wide array of products and services. They are the best placed actors to ensure effective Perception and Utilizing of Indigenous Environmental Protection Ethics. Local involvement would bring in important considerations of Indigenous Environmental Protection Ethics [16].

\section{Findings}

There are many definitions and descriptions of Indigenous Environmental Protection Ethics. Most of these are helpful, but none seem to completely capture the full concept [17]. The indigenous peoples of Bale Oromo possess an immense knowledge of their environments, based on centuries of living close to nature. Living in and from the richness and variety of complex ecosystems, they have an understanding of the environments. Equally, people's knowledge and perceptions of the environment, and their relationships with it, are often important elements of cultural identity [18] [19].

Indigenous environmental Ethics is a body of moral knowledge and beliefs transmitted through oral tradition and first-hand observation. It includes a system of classification, a set of empirical observations about the local environment, and a system of self-management that governs resource use [20].

To acquire a deep understanding of Indigenous Environmental Protection Ethics and to be able to use it responsibly in estimating impacts on the environment or on the culture of the people requires a lifetime of concentration. Just as with the development of scientific expertise, which also requires decades of immersion and practical experience to be highly accurate in predictions, a great investment of time is needed. While it is entirely possible to gather the facts and information contained in the traditions, it is much more difficult to understand the relationships that are contained in the generations of teachings.

Recognize that Indigenous Environmental Protection Ethics is a way of life, an experience-based relationship with family, spirits, animals, plants, and the land, an understanding and wisdom gained through generations of observation and teaching that uses indirect signals from nature or culture to predict future events 
or impacts [4] [20]. An indigenous environmental ethic is the set of values and beliefs of an individual or group of people relating to the environment. It involves individuals' or people's attitudes towards the environment (Workeneh, 2011).

Environmental crises cannot be solved only by appealing to modern environmental ethics or any other environmental theory. The role of indigenous environmental ethics should be given due attention. The World Commission on Environment and Development regards indigenous knowledge as a significant variable and a critical factor in achieving sustainable development.

"Workeneh, 2011, stated that the Oromo people believe that the present generation is under a moral obligation to preserve the land and hand it over to future generations. One of the bases of this obligation is the belief that a person should not endanger the prospects of future generations by destroying the land. One has to make sure that his or her lineage will continue to flourish in the future. The society condemns those who deprive their children and their children's children. The other important basis of obligation is that Waaqa will punish those who disregard the cosmic order and unnecessarily exploit the land and its resources. The land is a blessing and the source of survival. Waaqa allows humans and other creatures to use the land. Accordingly, the people should not ravage the actual purpose of Waaqa and the whole history and order of things. Thus, the Oromo people believe that if one does not look after the land, one is not only frustrating his own desire instrumentally to have good land in the future but one is also undermining future generations and the cosmic purpose" [8].

Bale Oromo have developed strong indigenous environmental protection ethics which is based on the laws of Waaqa (GOD) as given in nature. The Oromo moral law (safuu) which is based on justice does not allow irresponsible and unlimited exploitation of resources and human beings. Indigenous environmental protection ethics are essential for communities' development and the health of the natural environment and its inhabitants [14].

For Oromo, particularly for Bale Oromo a sick environment cannot be the living space for creatures [14]. The findings of this study suggest that the study of an indigenous environmental protection ethics in different parts of Oromia and elsewhere in Ethiopia is very important. Hence, I would suggest that various experts should come together and undertake systematic study of indigenous environmental protection ethics and science on the basis of multi-disciplinary approaches. If we delay the study of indigenous environmental protection ethics and its impact on the development process and environmental management, it will disappear together with its invaluable possessors.

\section{Conclusions}

Ethics investigates deep connections and moral commitments between nonhumans and humans to guide ethical forms of environmental decision making and environmental protection. Indigenous environmental protection ethics is closely 
related to the daily life of people, particularly for Bale Oromo society. Indigenous environmental protection ethics is recognized as having relevance to Bale Oromo people's daily life, economic development, and environment preservation. Bale Oromo has a rich culture of natural resource conservation which can be optimized to meet the challenges of the day.

The struggle for environmental protection and justice should go hand in hand with the struggle for self-determination, and democracy; our soils, forests, water resources, and in general all our environmental resources deserve all the necessary indigenous environmental protection measures. Without them, our souls will be empty and our material being will disappear.

Constraints of utilizing indigenous environmental protection Ethics are that indigenous technology and practice are not universally applicable, but are locally grounded. Because of the localization of indigenous knowledge systems, the local people do not have the intellectual resources to engage with global issues created by capitalism.

Various environmental theories have valuable insights and can contribute to the solution of environmental problems in different ways. A variety of perspectives and values are useful in understanding environmental problems and the place of humans within nature. Environmental problems require global concerns and cannot be solved by one nation or one single approach alone. It has to be noted that if we simply defend the intrinsic value of different things and ignore the interests of humans, our position will be vulnerable to attack and remain mere speculation without any relevance to the real environmental problems in the world.

\section{Conflicts of Interest}

The author declares no conflicts of interest regarding the publication of this paper.

\section{References}

[1] Andrew, L. (2003) Anthology of Environmental Ethics. Blackwell Publishing Company, New York.

[2] Asafa, J. (2010) Oromo People Hood: Historical and Cultural Overview. Sociological Publication and Other Works.

[3] Hayden, C. (1994) When Nature Goes Public. The Making and Unmaking of Bioprospecting in Mexico. Princeton University Press, Princeton, NJ.

[4] Hausler, S. (1995) Listening to the People: The Use of Indigenous Knowledge to Curb Environmental Degradation. In: Stiles, D., Ed., Social Aspects of Sustainable Dryland Management, John Wiley and Sons, Chichester, 179-188.

[5] Callicott, J.B. (2000) Many Indigenous Worlds or the Indigenous World? A Reply to My 'Indigenous' Critics. Environmental Ethics, 22, 291-310. https://doi.org/10.5840/enviroethics200022319

[6] Stenmark, C., et al. (2002) Consequences, Identification in Forecasting and Ethical Decision-Making. Journal of Empirical Research on Human Research Ethics, 6, 25-32. 
[7] Gemetchu, M. (2005) Oromo World View. Journal of Oromo Studies, 12, 68-79.

[8] Kelbessa, W. (2011) Indigenous and Modern Environmental Ethics: A Study of the Indigenous Oromo Environmental Ethic and Modern Issues of Environment and Development. In: Cultural Heritage and Contemporary Change Series II. Africa, Volume 13, Council for Research in Values and Philosophy, Washington DC, 1-235. https://doi.org/10.1093/oxfordhb/9780195328998.003.0049

[9] Baxter, P.T.W. (1993) One Possible New Perspective for Oromo Nationalism. Proceedings of the Oromo Studies Association: International Conference on Resource Mobilization for the Liberation of Oromia, University of Toronto, Ontario, Canada, 31 July-1 August 1993.

[10] Atteh, O.D. (1992) Indigenous Local Knowledge as Key to Local Level Development: Possibilities, Constraints and Planning Issues in the Context of Africa. Iowa State University Research Foundation, Leiden.

[11] Omari, C.K. (1990) Traditional African Land Ethics. In: Engel, J.R. and Engel, J.G., Eds., Ethics of Environment and Development. Global Challenge, International Response, Belhaven Press, London, 167-75.

[12] Baissa, L. (2004) The Oromo Gadaa System of Government: An Indigenous African Democracy. New York.

[13] Ojomo, P. (2011) Environmental Ethics: An African Understanding. African Journal of Environmental Science and Technology, 5, 572-578. https://doi.org/10.4314/tp.v2i2.64100

[14] Hassen, M. (1994) Some Aspects of Oromo that Have Been Misunderstood. Journal of Oromo Studies, 1, 77-90.

[15] Legesse, A. (1973) Gadaa: Three Approaches to the Study of African Society. Free Press, New York.

[16] Legesse, A. (2000) Oromo Democracy: an Indigenous African Political System. The Red Sea Press, Inc., Asmara.

[17] Rolston, H. (1988) Environmental Ethics: Duties to and Values in the Natural World. Temple University Press, Philadelphia, PA.

[18] Shrader-Frechette, K. (2002) Environmental Justice: Creating Equality, Reclaiming Democracy. Oxford University Press, New York.

[19] Degie, T. (2017) Dealing with Environment: Indigenous Environmental Ethics, Ethiopia. International Journal of Philosophy, 5, 36.

[20] Taylor, P.W. (1986) Respect for Nature: A Theory of Environmental Ethics. Princeton University Press, Princeton, NJ. 